\title{
SOMATIC INSTABILITY OF CHROMOSOME NUMBER IN HYMENOCALLIS CALATHINUM
}

\author{
BRIAN SNOAD \\ John Innes Horticultural Institution, Bayfordbury, Hertford, Herts.
}

Received s.vii. 54

\section{OBSERVATIONS}

IN the genus Hymenocallis the basic chromosome number appears to be 23 notwithstanding that in different species the chromosomes have quite different forms. They can be classified into two distinct groups by their chromosome complements. First, there is the complement where the chromosomes have mainly median or sub-median centromeres. Secondly, there is the complement where many of the chromosomes have terminal or nearly terminal centromeres. This complement, however, has been reported only in the tetraploid or near tetraploid forms. The chromosome numbers of these species are as follows* :-

\section{Metacentric Group-}

\begin{tabular}{|c|c|c|}
\hline H. amancaes & $2 n=46$ & \\
\hline H. littoralis & $2 n=46$ & (Sato, I938) \\
\hline H. lacera & $2 n=69$ & (Sato, I938) \\
\hline H. senegambica & $2 n=69$ & $t$ \\
\hline H. harrisiana & $2 n=87$ & $\dagger$ Fig. IA \\
\hline H. speciosa & $2 n=\left\{\begin{array}{l}46 \\
90-100\end{array}\right.$ & $\begin{array}{l}\text { (Sato, I938) } \\
\text { (Heitz, I926) }\end{array}$ \\
\hline
\end{tabular}

Partly Telocentric Group-
H. macrostephana
$2 n=92$
Fig. IB (Snoad, I95I)
H. $\times$ Daphne $(H$. cala- thinum $\times H$. speciosa)
$2 n=92$
$\dagger$

The second of these two types of chromosome complement has presumably evolved from the other by fragmentation. Subsequent hybridisation has introduced a basic number which happens to be a multiple of the original one but is composed of different chromosome types. This explains the absence of diploid plants with telocentrics.

* Root tips for squash preparations were fixed in La Cour's 2 BD and after one hour an equal quantity of 1 per cent. chromic acid was added to this fixative. Next day the roots were thoroughly washed in distilled water and treated in I part 20 vol. hydrogen peroxide and 3 parts saturated solution of ammonium oxalate for five minutes (Dr C. E. Ford, unpub.). The normal procedure for Feulgen squashes followed. $0 \cdot 05$ per cent. colchicine was used for the pre-treatment of root tips for some of the squash preparations.

Roots for embedding were fixed in La Cour's $2 \mathrm{BD}$, embedded, sectioned at $16-18 \mu$ and stained with crystal violet. Pollen mother cells were treated as Feulgen squashes after fixation in acetic alcohol $(1: 3)$.

$\dagger$ New count. 
There is a great range of basic numbers in the Amaryllidaceae and Hymenocallis would seem to be at the end of an evolutionary series rising from 6 to 23 .

In addition to those species already mentioned, Hymenocallis calathinum is also found to contain many telocentric type chromosomes. An attempt to determine its chromosome number, however, can be very confusing. Four plants of one clone were examined. The cells in the root tips contain different numbers of chromosomes. The variation is from 23 to 83 chromosomes though the lower and consequently more unbalanced complements are far less frequent than the higher ones (graph 1). The examination of these complements does not reveal any pattern of chromosome distribution. They are

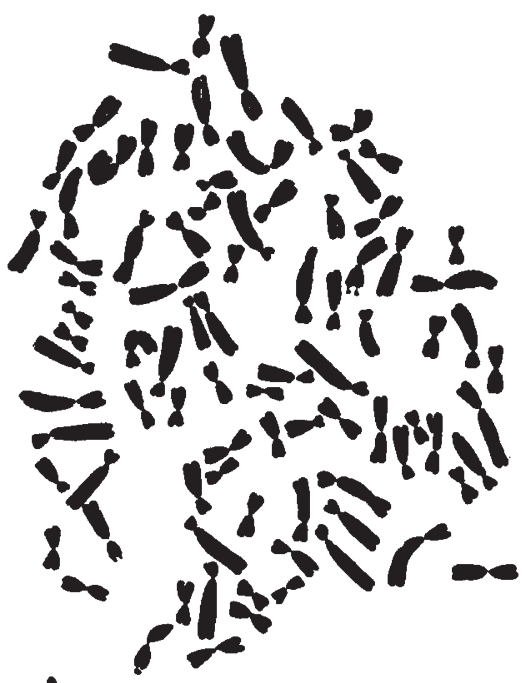

A

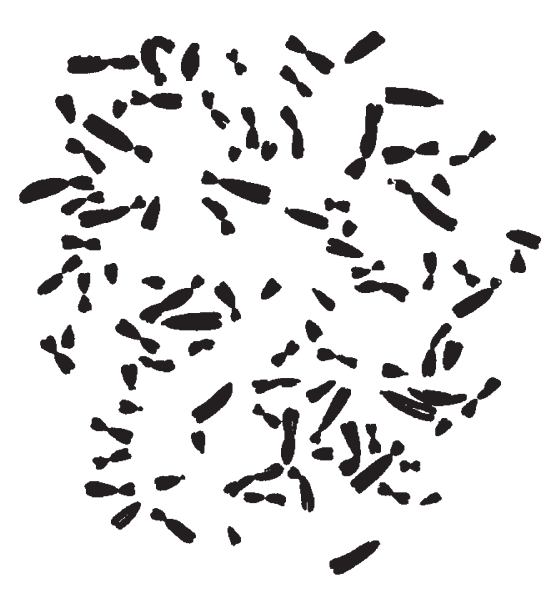

B

Fig. I.-Root-tip mitoses.

(A) Hymenocallis harrisiana $(2 n=87)$. All metacentric chromosomes. $\times 1050$.

(B) $H$. macrostephana $(2 n=92)$. Complement includes 27 telocentric chromosomes. $\times 1050$.

not apparently segregated into multiples of any basic number but distributed more at random. Similarly the abnormal cells are not confined to any one region of the root.

In colchicine-treated squash preparations of root tips many of the metaphase nuclei are obviously unusual. The shortened chromosomes are often segregated into two, or even three, distinct groups (plate, fig. 2) suggesting an irregular grouping of the chromosomes and the formation of separate nuclei at the previous telophase. Even taking the spindle inhibiting effect of the colchicine into account this peculiarity appears unusually evident. Accordingly, preparations of roots without pre-treatment-both sectioned and squashed--have been examined. Spindle abnormalities are then seen (plate, figs. 3 and 4). Some cells have two distinctly separate spindles and others 
tripolar ones. In addition, many micronuclei of varying size are to be seen. The variability of the chromosome number is thus explained.

These split spindles allow the unhampered separation of the chromatids and their passage to the poles. At telophase, however, in many cells, presumably because of insufficient room, there is often

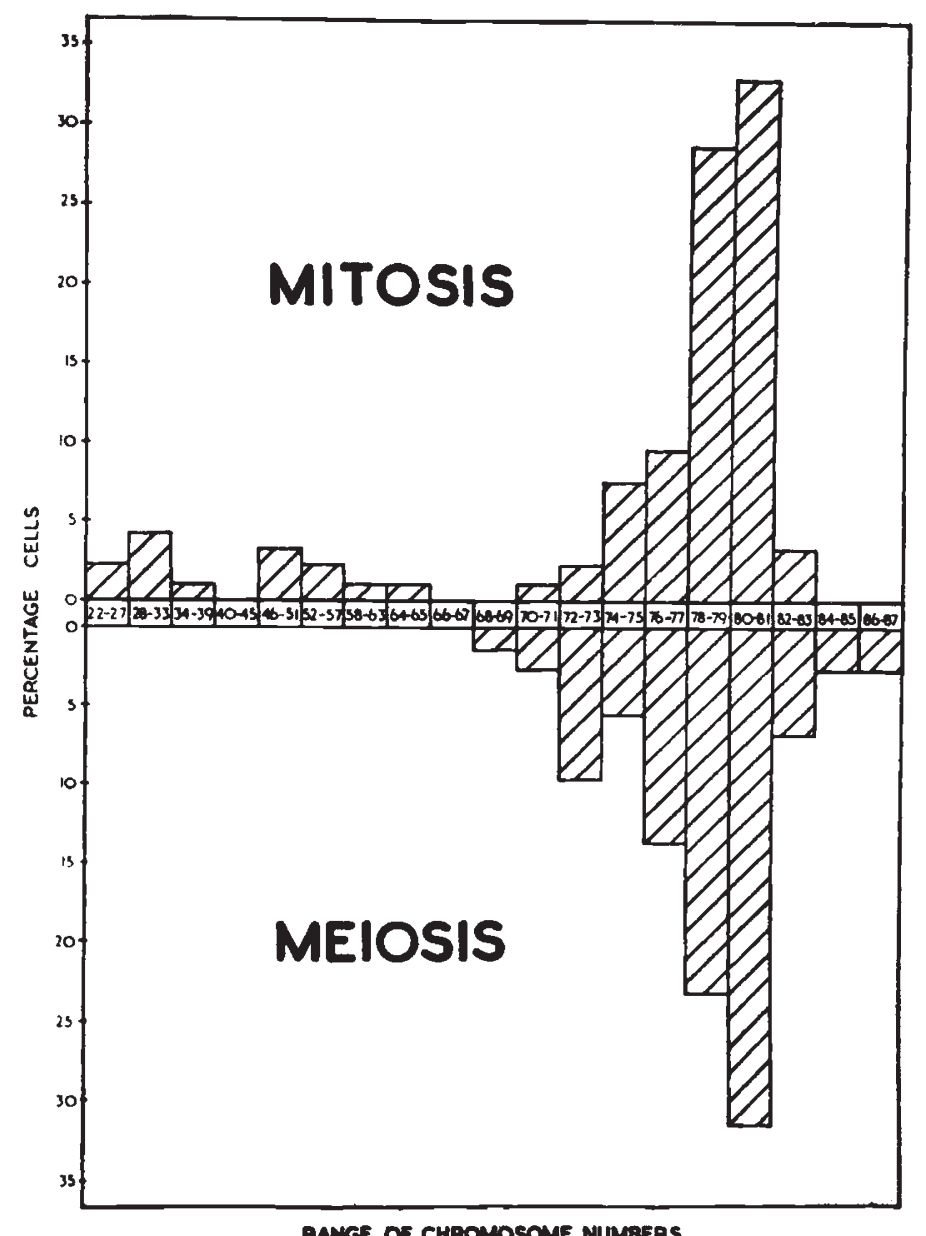

GRAPH 1.-Showing the frequency of different chromosome complements in $H$. calathinum at mitosis ( 94 cells counted) and meiosis ( 73 cells counted).

fusion of these irregularly distributed daughter groups. As a result two or more groups become enclosed within one cell wall and the higher chromosome numbers are restored. It is also highly likely that nuclei with low numbers are shortlived because of extreme unbalance.

This variation in chromosome number is also carried through the germ line so that the pollen mother cells contain differing numbers of chromosomes. The range of numbers at meiosis is smaller than 
that at mitosis (graph I). This provides further evidence of the instability of the smaller chromosome complements. The premeiotic cells have probably carried the variation through many cell generations but the conditions only permit the larger and more balanced numbers to propagate themselves.

The highest number of univalents seen in any pollen mother cell was four. This can perhaps be attributed to somatic pairing of the chromosomes so that spindle abnormalities lead to the segregation of mainly homologous pairs rather than to a random distribution. Somatic pairing has also been inferred in Helianthemum (Snoad, 1954) where, in some plants, meiotic pairing of reduced chromosome complements was higher than would be expected on random splitting of the spindle.

\section{DISCUSSION}

That the number of chromosomes within individuals-both plants and animals-is not wholly constant has been quite widely reported. These reports, however, deal mainly with increases in chromosome number to give multiples of the basic number. Thus, endomitosis has been observed in the tapetal cells of tomato (Brown, 1949) and Spinacia (Witkus, 1945) and also in the nurse cells of the ovary of Drosophila melanogaster (Painter and Reindorp, 1939). Polyploid and mixoploid tissues have been observed in the nymphs of Romalea microptera (Mickey, 1946). Polyploid cells have also been reported in mammals-in the liver (Biesele, 1944) and in the blood (La Cour, 1944).

The frequency of reduced chromosome numbers within individuals is not so great. In adult human uterine epithelium in its proliferative stage and various embryonic tissues-skin, brain, liver, connective tissue, intestine, etc.-great sub-diploid variation has been found (Therman and Timonen, I95I). This variation was denied by Sachs (1954). He examined the normal endometrium in Homo sapiens, Rattus norvegicus and Microtus agrestis but no sub-diploid variation was apparent. The presence of polyploid cells was, however, confirmed.

A very wide range of chromosome numbers was found in colchicineinduced tetraploid Ribes nigrum bushes and in their progeny raised from seed (Vaarama, 1949). The chromosome numbers in the root tips varied from 4 to 32 . The cause of this variation was attributed to the presence of two separate spindles in the cells-a similar condition to that in Hymenocallis.

Another report of chromosome mosaicism, this time of pollen mother cells, is that of Sachs (1952). It was found in 19 out of 24 amphiploids in Triticum, Aegilops and Agropyron. The reduced chromosome numbers ranged from 9 to 48 in the $8 x$ plants and to to 40 in the $6 x$ ones. As there were no mosaics in the root tips of these plants the presumed spindle abnormalities must have occurred late in development, i.e. during the premeiotic mitoses. 


\section{Plate}

Mitosis in the root tips of Hymenocallis calathinum. Feulgen squash method.

Fig. I.-Colchicine-treated metaphase showing a highly reduced chromosome number of $34 . \times 1040$.

Fig. 2.-Metaphase after colchicine treatment showing the segregation of the chromosomes into two distinct groups. $\times 1400$.

Fig. 3.-Upper cell with a tripolar spindle, lower one with three separate spindles. $\times 104^{\circ}$.

Fig. 4.-Two separate spindles within one cell. $\times$ 1040. 
איis
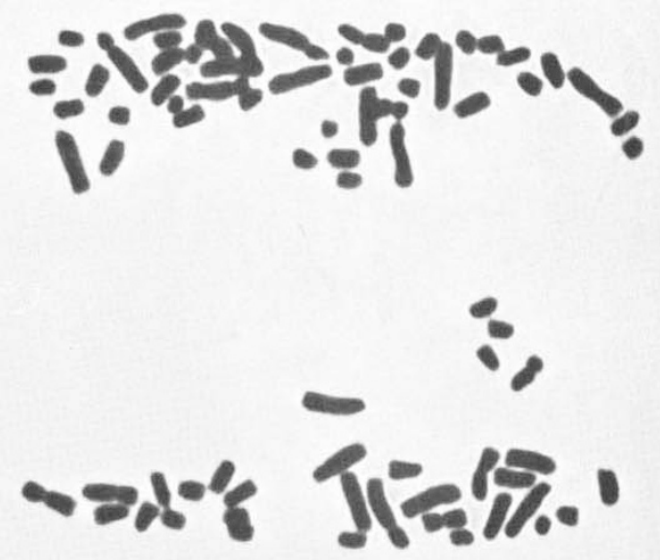

$x^{4}+\frac{62}{4}$

2
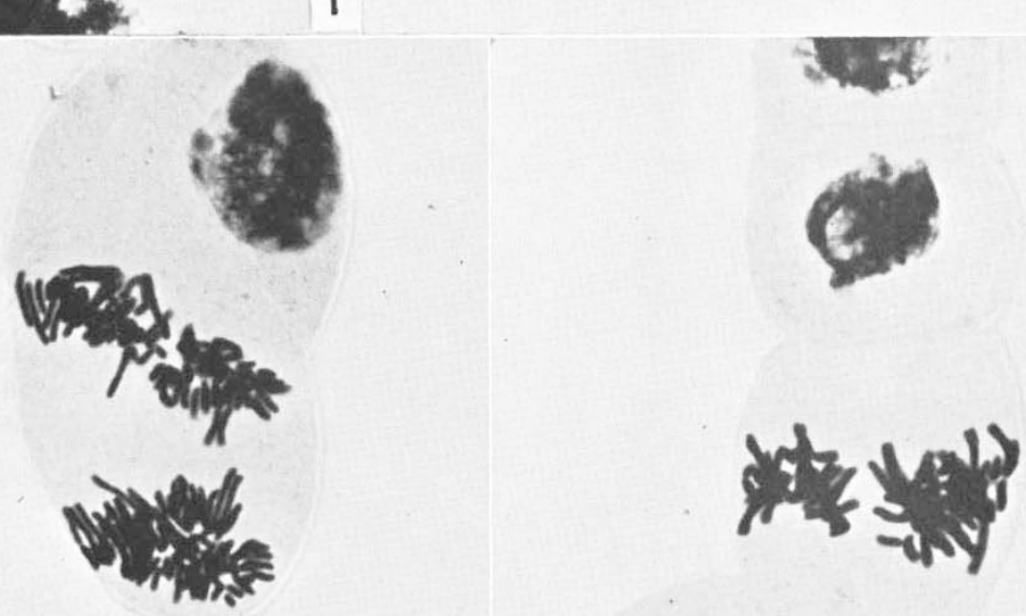

p.
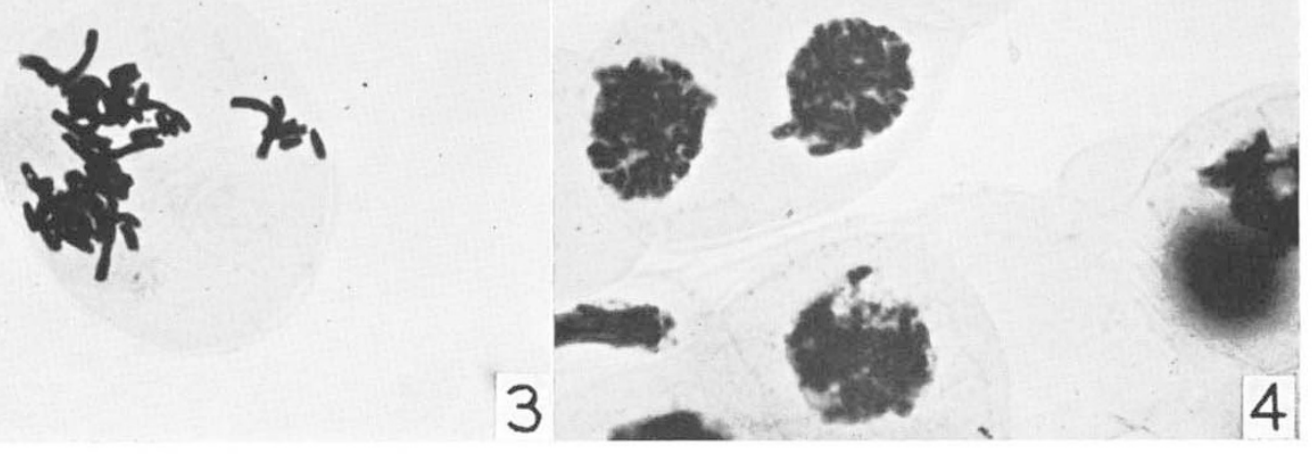
Sub-diploid variation of chromosome numbers has also been found in the pollen mother cells of Helianthemum (Snoad, 1954). Here also the spindle disturbances are assumed to have occurred during several premeiotic mitoses but they are also associated with a failure of wall formation so that plasmodial pollen mother cells are formed.

The nuclear behaviour in $H$. calathinum follows the pattern laid down by many of these examples. A disorganisation of the spindle's function brings about a variation in chromosome number but in Hymenocallis this variation appears to be more widespread than in any other organism so far investigated. As in the only other root-tip variation (Ribes) the high chromosome number may not only be responsible for the origin of the spindle abnormalities but also for the survival of so many nuclei with reduced chromosome numbers.

\section{SUMMARY}

I. No constant chromosome number is to be found in the root tips of Hymenocallis calathinum. The numbers found range from 23 to 83 .

2. A variation over a smaller range-from 69 to 86 chromosomesis also found in the pollen mother cells.

3. Spindle abnormalities are seen to give rise to this variation in chromosome number.

4. There are different levels of tolerance to unbalanced chromosome numbers in anthers and roots.

Acknowledgment.-I wish to thank Mr L. F. La Cour for his helpful criticism and advice.

\section{REFERENCES}

Bresele, J. J. 1944. Chromosome complexity in regenerating rat liver. Cancer Research, 4, 232-235.

Brown, s. w. 1949. Endomitosis in the tapetum of tomato. Amer. F. Botany, 36, 703-716.

HEITZ, E. I926. Hab. Schr. Hamburg. cit T., I927.

LA cour, L. F. 1944. Mitosis and cell differentiation in the blood. P.R.S. Edin., $\mathrm{B}, 62,73-85$.

MICKEY, G. H. 1946. Endomitosis in tissues of the Louisiana lubber grasshopper, Romalea microptera (Beauv.). Rec. Genet. Soc. Am., No. I5, p. 6 o.

PAINTER, T. S., AND REINDORP, E. C. 1939. Endomitosis in the nurse cells of the ovary of Drosophila melanogaster. Chromosoma, $1,276-283$.

SACHS, L. 1952. Chromosome mosaics in experimental amphiploids in the Triticinae. Heredity, 6, I 57-1 70.

SACHS, L. 1954. The chromosome constancy of the normal mammalian uterus. Heredity, 8 , I 1 7-1 24 .

SATO, D. 1938. Karyotype alteration and phylogeny. IV. Karyotypes in Amaryllidaceae with special reference to the SAT chromosome. Cytologia, 9, 203-242.

SNOAD, B. 1951. Forty-second annual report of the John Innes Hort. Inst. 
SNOAD, B. 1954. Abortive meiosis in plasmodial pollen mother cells of Helianthemum. Ann. Bot. N.S., r8, No. 69, pp. I-6.

THERMAN, E., AND TIMONEN, s. I95I. Inconstancy of the human somatic chromosome complement. Hereditas, 37, 266-279.

VAARAMA, A. 1949. Spindle abnormalities and variation in chromosome number in Ribes nigrum. Hereditas, 35, 1 36-162.

witkus, E. R. 1945. Endomitotic tapetal cell divisions in Spinacia. Amer. F. Bot., 32, 326-330. 